\author{
환원 산화 그래핀을 이용한 계면제어가 \\ 다결정 $\mathrm{SnSe}$ 의 열전 수송특성에 미치는 효과 \\ 이상태 · 임영수* \\ 부경대학교 신소재시스템공학과
}

\title{
Effects of Interface Control Using Reduced Graphene Oxide (RGO) on the Thermoelectric Transport Properties of Polycrystalline SnSe Compounds
}

\author{
Sang Tae Lee and Young Soo Lim* \\ Department of Materials Syetem Engineering, Pukyong National University, Busan 48547, Republic of Korea
}

\begin{abstract}
We report the effects of interface control using reduced graphene oxide (RGO) on the thermoelectric transport properties of polycrystalline SnSe compounds. Polycrystalline SnSe-RGO composites were prepared by the consolidation of SnSe powder coated with the RGO by hot pressing, and the RGO content was controlled to be $0,0.2,0.5$ and $1 \mathrm{wt} \%$. The incorporation of RGO did not induce any structural changes in the crystal structure of SnSe, and no additional secondary phase could be observed. The electrical conductivity of the composites increased with increasing RGO content. This increase was largely the result of increased hole concentration due to the hole Fermi liquid phenomenon at the SnSe-RGO interface, and it was elucidated by the reduced Seebeck coefficient with increasing RGO content. However, this tendency could only be clearly observed at relatively low temperatures, and the incorporation of the RGO did not lead to a significant increase in the power factor. The thermal conductivity of the composites decreased with the increase in RGO content, and revealed that there was additional phonon scattering at the grain boundary interfaces due to the existence of the RGO. These results, demonstrated that independent control of charge and thermal transport, i.e., phonon glass-electron crystal, could be realized by interface control using RGO in polycrystalline SnSe compounds.
\end{abstract}

(Received October 18, 2017; Accepted November 6, 2017)

Keywords: thermoelectric, SnSe, reduced graphene oxide, hot pressing, interface control

\section{1. 서 론}

온도차를 전기에너지로 변환하는 제벡(Seebeck) 효과와 함께 전위차를 활용하여 열을 이동시키는 펠티어(Peltier) 효과를 포함하는 열전변환기술은 움직이는 구동부 없이 고 상의 열전소재 내에서 직접 가역적으로 열과 전기 에너지 의 변환을 가능하게 하는 에너지 기술이다 $[1,2]$. Goldsmid에 의해 처음으로 근대적 열전기술이 실현된 이 후, 제한된 화석에너지의 효율적 사용과 함께 $\mathrm{CO}_{2}$ 발생 감소를 통한 지구온난화 억제, 그리고 전자냉각기술을 이 용한 다양한 냉각 및 방열기기 활용에 이르기까지 열전기

*Corresponding Author: Young Soo Lim [Tel: +82-51-629-6384, E-mail: yslim@pknu.ac.kr] Copyright (C) The Korean Institute of Metals and Materials
술에 대한 관심은 지속적으로 높아져왔다 [3]. 열전변환 효율 은 열전소재의 성능에 심각하게 의존하며, 열전소재의 성능 은 무차원 열전성능지수인 $Z T\left(=S^{2} \sigma T / \kappa, S\right.$ 는 제벡 계수, $\sigma$ 는 전기전도도, $T$ 는 절대온도, $k$ 는 열전도도) 로 나타내어진다 . 따라서 열전소재의 성능향상을 위하여 열 및 전하수송특 성을 제어하는 연구가 지속적으로 추진되어 왔으며, 특히 $\mathrm{Bi}_{2} \mathrm{Te}_{3}$ 및 $\mathrm{PbTe}$ 계 열전소재에서 나노구조화를 통한 열전 수 송특성 제어는 열전성능지수의 비약적 향상을 가져왔다 [4$12,44,45]$.

이러한 기존 열전소재의 성능항상에 대한 연구 이외에도 값이 저렴하고 독성이 없는 신규 열전소재에 대한 탐색이 지속적으로 이루어져 왔으며, 이 중에서 특히 ZT가 2.0이 넘는 $\mathrm{SnSe}$ 가 최근들어 큰 주목을 받고 있다 [13-29]. $\mathrm{SnSe}$ 는 열전도도와 전기전도도에 있어서 매우 큰 이방성 
을 지니는 물질로, $\mathrm{a}$ 축 방향의 열 및 전기전도도가 $\mathrm{b}$ 및 c축 방향에 비해 매우 낮은 특징을 가지고 있다. 2014년 Zhao 등은 $\mathrm{SnSe}$ 단결정의 $\mathrm{b}$ 및 $\mathrm{c}$ 축 방향에서 각각 2.6 과 2.3 의 높은 $Z T$ 를 $923 \mathrm{~K}$ 의 온도에서 구현한 바 있으며, 또 한 이방성으로 인하여 c축 방향에서는 0.8 정도의 상대적 으로 낮은 ZT값을 보고하였다 [13]. 이러한 우수한 열전 성능에도 불구하고 $\mathrm{SnSe}$ 단결정의 취약한 기계적 특성으 로 인하여 다결정 $\mathrm{SnSe}$ 의 개발이 매우 요구되어지며, 또한 결정립계에서 추가적인 포논산란에 의한 추가적인 열전도 도 감소를 기대할 수 있기 때문에 다결정 $\mathrm{SnSe}$ 에 대한 관 심이 매우 고조되어 왔다. 그러나, 예상과 달리 다결정 $\mathrm{SnSe}$ 의 경우에는 높은 열전도도로 인하여 단결정에 비해 상대적으로 낮은 열전성능지수가 보고되고 있다 $[16,19,26]$. 그 이유가 아직 명확하게 규명되지는 않았지만, Chen 등 의 연구에 따르면 제조 과정에서 $\mathrm{SnSe}$ 분말이 산소에 불 가피하게 노출되면서 입계에 $\mathrm{Sn}$ 산화물이 형성되고 이 산 화물의 높은 열전도도 $\left(300 \mathrm{~K}\right.$ 에서 $\left.~ 98 \mathrm{Wm}^{-1} \mathrm{~K}^{-1}\right)$ 로 인하여 다결정 $\mathrm{SnSe}$ 의 열전도도를 증가 시킨다는 것이 최근 보고 되었다 [30]. 그럼에도 불구하고, 다결정 $\mathrm{SnSe}$ 의 $Z T$ 를 향 상시키는 방법으로 이종의 원소를 도핑함으로써 출력인자 의 향상을 시키는 연구와 함께 $\mathrm{SnS}$ 또는 $\mathrm{SnTe}$ 와의 합금 화를 통해 열전도도를 감소시키는 연구들이 보고되어져 왔 으며, 특히 칼륨을 도핑한 다결정 $\mathrm{SnSe}$ 에서 균일한 나노석 출물 형성을 통해 단결정 $\mathrm{SnSe}$ 와 유사한 낮은 열전도도를 구현하여 $773 \mathrm{~K}$ 의 온도에서 1.1 의 우수한 $Z T$ 가 보고된 바 있다 [30].

한편, 탄소원자가 $\mathrm{sp} 2$ 혼성화를 통해 육각형 격자로 배 열된 2차원 물질인 그래핀은 큰 비표면적 (> $2000 \mathrm{~m}^{2} / \mathrm{g}$ ), 높은 열전도도 $(\sim 5000 \mathrm{~W} / \mathrm{mK})$, 높은 이동도 $(\sim 20,000$ $\left.\mathrm{cm}^{2} / \mathrm{Vs}\right)$, 유연성, 내투과성 등 기존 소재에서는 관찰되지 않던 특이한 성질들로 인하여 오늘날 가장 중요한 나노물 질 중 하나로 주목을 받고 있다 [31-33]. 우리 연구 그룹 에서는 이러한 그래핀을 열전소재 분말에 코팅하여 그래핀 복합 열전소재 분말 제작한 후 이를 소결하여 그래핀-열전 소재 복합체를 제작할 경우, 전기전도도의 증진과 동시에 입계에 존재하는 그래핀의 포논 산란에 의해 열전도도가 감소하는 현상을 보고해 왔다 [34-36]. 본 연구에서는 다결 정 $\mathrm{SnSe}$ 의 열전성능 향상을 위하여 다결정 $\mathrm{SnSe}$ 의 입계를 그래핀으로 코팅함으로써 포논 유리전자 결정(phonon glass-electron crystal, PGEC)를 구현하는 연구전략을 시도 하였으며, 본 실험을 위한 그래핀은 산화 그래핀(graphene oxide, $\mathrm{GO}$ )을 환원시켜 제조한 환원 산화 그래핀(reduced graphene oxide, RGO)를 이용하였다. 이를 통해 제작된
$\mathrm{SnSe}-\mathrm{RGO}$ 복합체에서 전기전도도의 상승과 열전도도의 저 감이 동시에 구현되었으나, 반면 제벡 계수의 급속한 저하 가 나타나 열전성능지수는 RGO 함량이 증가함에 따라 감 소하는 현상이 관찰되었다. 그러나 본 연구를 통해 그래핀 복합화를 통한 열전도도와 전기전도도의 독립적 제어가 가 능하다는 사실을 확인하였으며, 이러한 연구전략은 향후 다 른 열전소재의 그래핀 복합화를 통한 열전성능 항상에 폭 넓게 활용될 수 있다고 여겨진다.

\section{2. 실험 방법}

본 실험에서는 먼저 진공 용융법을 이용해 $\mathrm{SnSe}$ 주괴 (ingot)을 제작하였으며, 출발 원료는 Sn $(99.999 \%$, shot, Alfa Aesar)과 Se $(99.999 \%$, shot, $5 \mathrm{~N}$ Plus)를 사용하였 다. 조성에 맞게 칭량한 $\mathrm{Sn}$ 과 $\mathrm{Se}$ 를 석영관에 넣은 후 약 $1.5 \times 10^{-2}$ Torr 정도의 진공도를 유지하면서 밀봉하였다. 밀봉된 석영관은 전기로에서 $1223 \mathrm{~K}$ 의 온도로 24시간 유 지 후 $773 \mathrm{~K}$ 까지 로냉시키고 이후 상온의 물에 급냉하였 다. 이와 같은 공정을 통해 제조한 주괴를 $\mathrm{Ar}$ 분위기의 글로브박스 내에서 유발을 사용해 분말로 분쇄한 후 200 $\operatorname{mesh}(\leq 74 \mu \mathrm{m})$ 로 체가름하였다.

이와 같은 방법으로 제작한 $\mathrm{SnSe}$ 분말에 그래핀을 코팅 하여 $\mathrm{SnSe}$-그래핀 복합 분말을 제조하였으며, $\mathrm{RGO}$ 의 함량 은 $0,0.2,0.5$ 및 $1 \mathrm{wt} \%$ 로 조절하였다. Dimethylformamide (DMF) 용매 $200 \mathrm{ml}$ 를 $1,000 \mathrm{ml}$ 플라스크에 넣고 reflux 관을 연결한 후 $\mathrm{SnSe}$ 분말을 플라스크에 넣고 5 분 간 히 팅맨틀에서 교반시켜 주었다. 다음으로 $\mathrm{GO}(5 \mathrm{~g} / \mathrm{L}$ in water)를 상기의 플라스크에 함께 투입하여 5 분간 교반시 킨 후, hydrazine monohydrate ( $\mathrm{GO}$ : hydrazine $=100$ $\mathrm{mg}$ : $4 \mathrm{ml}$ 를 넣고 $80^{\circ} \mathrm{C}$ 의 온도에서 1 시간 동안 산화 그래핀을 환원시켰으며, 이를 다시 비이커에 옮겨 24시간 동안 숙성(aging)을 수행하였다. 원심분리기를 사용해 $10,000 \mathrm{rpm}$ 으로 10 분간 원심분리하여 $\mathrm{SnSe}-\mathrm{RGO}$ 복합분 말을 회수한 후, 마지막으로 진공오븐에서 $40{ }^{\circ} \mathrm{C}$ 의 온도로 24시간 동안 건조시켰다.

이와 같이 제조된 $\mathrm{SnSe}-\mathrm{RGO}$ 복합분말은 열간 압축 소 결법(hot pressing)을 이용해 소결하였다. 직경이 $12.5 \mathrm{~mm}$ 인 흑연 다이에 복합분말을 장입한 후, 금형(mold)에 연결 한 열전대와 챔버 내의 열전대를 이용하여 소결 온도를 측 정하였으며, $1 \times 10^{-4}$ Torr 진공 분위기를 유지하면서 $773 \mathrm{~K}$ 에서 110 분 간 소결하였다. 승온 속도는 분당 $10 \mathrm{~K}$ 이며, $60 \mathrm{MPa}$ 의 압력을 가하였다. 이상의 $\mathrm{SnSe}-\mathrm{RGO}$ 복 합체 제조방법을 그림 1 의 모식도에 간략하게 나타내었다. 


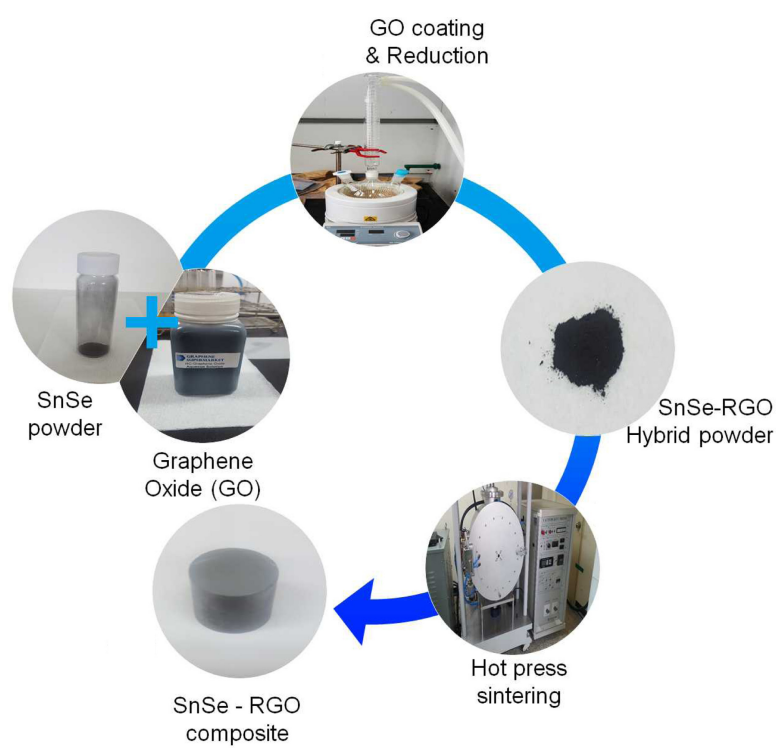

Fig. 1. Schematic of the experimental procedure for the SnSe-RGO composites.

소결체의 밀도는 아르키메데스(Archimedes) 법으로 측정 하였으며 상분석은 상온에서 $\mathrm{Cu} \mathrm{Ka}$ 방사를 사용하여 X선 회절(X-ray diffraction, XRD, Ultima 4, Rigaku)을 활용 하여 수행하였다. 전기전도도와 제벡 계수는 4탐침법(4 point probe method, ZEM-3, ULVAC-RIKO)을 사용하여 $300 \mathrm{~K}$ 에서 $900 \mathrm{~K}$ 까지 측정하였으며, 열전도도는 레이저 섬 광법(laser flash, LFA, DLF-1300, TA Instruments)을 활 용하여 측정하였다.

\section{3. 결과 및 고찰}

그림 2(a)는 이상과 같은 방법으로 제작된 $\mathrm{SnSe}-\mathrm{RGO}$ 복합체의 XRD 패턴을 보여준다. 그림의 삽도에 나타낸 바와 같이 모든 시료는 열간 압축 소결 공정의 가압방향 으로 측정되었다. 모든 패턴에서 사방정(orthorhombic) 구 조 $\left(P_{n m a}\right)$ 를 가지는 단일상의 $\mathrm{SnSe}(\mathrm{JCPDS}$ \#48-1224)가 관 찰되었다. $\mathrm{RGO}$ 의 함량에 따른 회절 피크의 이동은 관찰 되지 않았으며, 또한 이차상 역시 전혀 관찰되지 않았다.

모든 시료에서 $\mathrm{SnSe}$ (400) 회절 피크가 가장 강하게 관 찰되었으나, $\mathrm{SnSe}$ 의 열전수송특성은 배향성에 매우 크게 의존하므로 이를 보다 자세하게 확인하기 위하여 a축 배향 에 대한 로트게링 배향도(Lotgering factor, LF)를 아래의 식 (1)-(3)을 활용하여 계산하여 그림 2(b)에 나타내었다 [37].
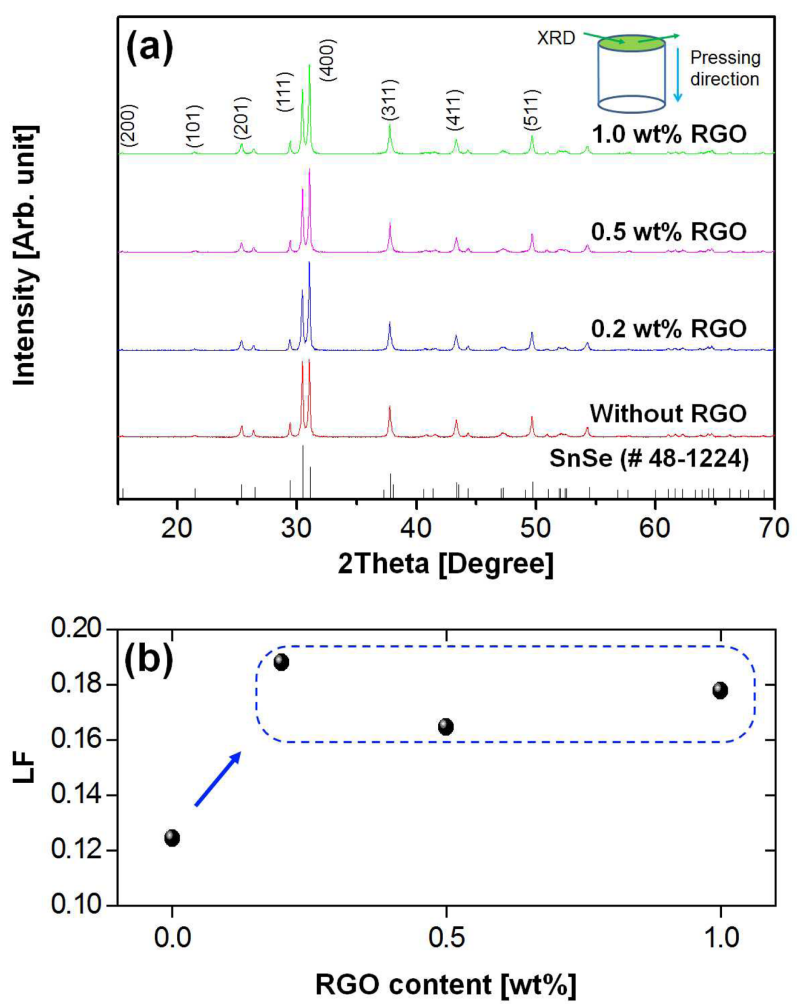

Fig. 2. (a) XRD patterns of the SnSe-RGO composites and (b) Lotgering factors of the composites as a function of RGO content.

$$
L F=\frac{p-p_{o}}{1-p_{o}}
$$

$$
\begin{aligned}
& 2 \theta \\
& p=\frac{\sum_{0} I_{h 00}}{2 \theta}, \\
& \sum_{0} I_{o, h k l} \\
& 2 \theta \\
& p=\frac{\sum_{0} I_{o, h 00}}{2 \theta} \text {, } \\
& \sum_{0} I_{o, h k l}
\end{aligned}
$$

여기에서 $I$ 와 $I_{o}$ 는 각각 대응하는 면에서의 실험 및 분말 회절 피크의 강도이다. 그림에서 보이듯 $(h 00)$ 의 LF는 $\mathrm{RGO}$ 가 존재하지 않을 경우 0.124 를 나타내지만, 각각 $0.2,0.5,1.0 \mathrm{wt} \% \mathrm{RGO}$ 가 들어간 시료에서는 각각 $0.188,0.165,0.178$ 로 가압방향에서의 $\mathrm{a}$ 축 배향성이 $33 \sim 52 \%$ 정도 증가한 양상을 나타낸다. 이러한 $\mathrm{SnSe}$ 의 $\mathrm{LF}$ 값들은 비록 방전 플라즈마 소결(spark plasma sintering, SPS) 방식으로 소결된 다결정 $\mathrm{SnSe}$ 의 값 


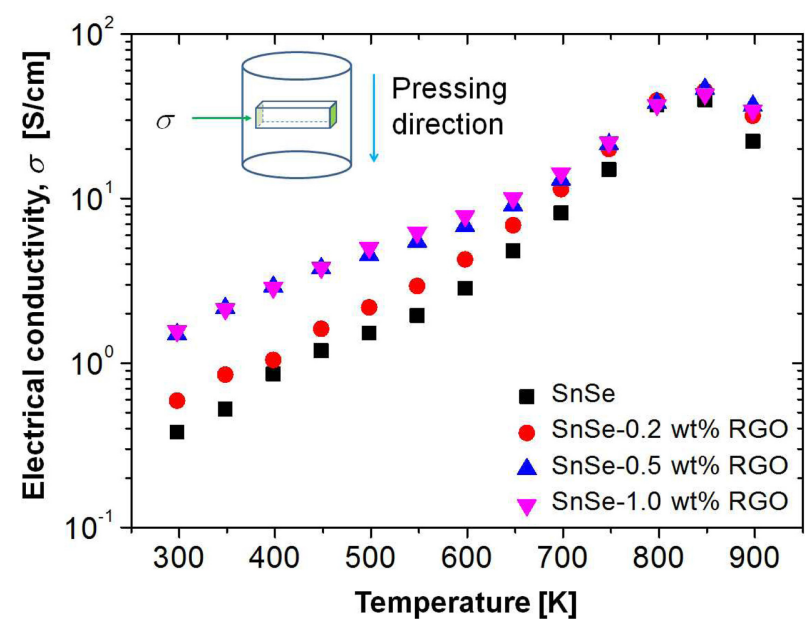

Fig. 3. Temperature-dependent electrical conductivities of the SnSeRGO composites in log-scale.

$(\sim 0.7)$ 과 비교할 때 상당히 낮은 수준이지만, $\mathrm{RGO}$ 가 다 결정 $\mathrm{SnSe}$ 의 배향성에 영향을 준다는 사실을 보여주며 이러한 현상의 원인 규명을 위하여 향후 추가 연구가 필 요하다고 생각된다 [38].

그림 3(a)는 SnSe-RGO 복합체의 온도에 따른 전기전 도도를 로그 스케일로 보여준다. 모든 시료에서 온도 증 가에 따라 전기전도도가 약 $800 \mathrm{~K}$ 까지 지속적으로 증가 하는데, 이는 $\mathrm{SnSe}$ 의 전하농도가 온도 증가에 따라 전 하농도가 증가하는 전형적인 비축퇴 반도체(nondegenerate semiconductor)임을 보여준다. $800 \mathrm{~K}$ 이상의 온도에서는 $P_{n m a}$ 상에서 $C_{m c m}$ 상으로 상전이로 인해 전자 -포논 산란이 심각하게 발생하여 온도증가에 따라 전기 전도도가 감소하는 현상이 관찰되었으며 [13,39], 이를 통 해 $\mathrm{RGO}$ 의 첨가가 $\mathrm{SnSe}$ 의 상전이에 큰 영향을 주지 못함을 알 수 있다.

한편 $\mathrm{RGO}$ 의 첨가에 따라 전기전도도가 약 한 order 정 도까지 비약적으로 증가하였는데, 이는 상대적으로 저온 영 역에서 보다 명확하게 관찰된다. 본 실험에서 전기전도도 는 삽도에 나타낸 것처럼 가압방향에 수직으로 측정되었기 때문에, 이러한 전기전도도 증가는 그림 2(b)에서 고찰한 바와 같이 $\mathrm{RGO}$ 증가에 따라 전기전도도가 가장 낮은 $\mathrm{a}$ 축 배향성이 감소하는데 기인했을 가능성도 존재한다 [13]. 그 러나, $0.2 \mathrm{wt} \%$ 의 $\mathrm{RGO}$ 가 들어간 시료와 그 이상의 $\mathrm{RGO}$ 가 첨가된 시료에서의 $\mathrm{LF}$ 값의 차이가 크지 않으므로 배 향성에 따른 전기전도도 증가효과는 크지 않다고 판단된 다. 또한, $\mathrm{RGO}$ 첨가에 따른 전기전도도 증가는 $\mathrm{RGO}$ 의 높은 이동도에 의해 기인하였을 수도 있다 [31-33]. 그러나 $0.5 \mathrm{wt} \%$ 와 $1 \mathrm{wt} \%$ 의 $\mathrm{RGO}$ 가 첨가된 시료의 전기전도도

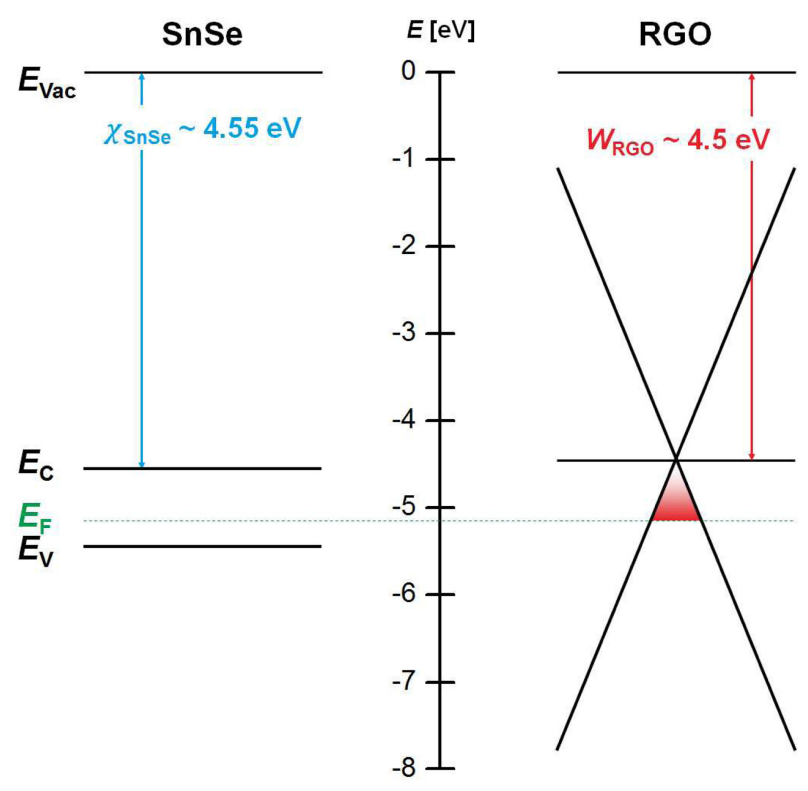

Fig. 4. A schematic band alignment of the SnSe-RGO composites $\left(\chi_{\mathrm{SnSe}}\right.$ : electron affinity of SnSe, $W_{\mathrm{RGO}}$ : Dirac point of RGO, $E_{\mathrm{F}}$ : Fermi level, $E_{\mathrm{C}}$ : conduction band of $\mathrm{SnSe}, E_{\mathrm{V}}$ : valence band of $\mathrm{SnSe}$, and $E_{\mathrm{Vac}}$ : vacuum level).

차이가 미미하며, 따라서 이는 전하농도의 변화가 전기전 도도의 비약적 증가의 가장 큰 원인임을 의미한다.

이러한 전하농도의 증가는 그래핀의 페르미 액체(Fermi liquid) 현상을 통해 설명할 수 있다 [40,41]. 그래핀의 전 하농도는 접촉하고 있는 물질의 페르미 준위(Fermi level) 에 의해 영향을 받는다. 접촉하고 있는 물질의 페르미 준 위이 그래핀의 일함수(work function)인 디랙 점(Dirac point) $(\sim 4.5 \mathrm{eV})$ 위에 위치할 경우 electron Fermi liquid 가 그래핀에 생성되며, 반면 접촉하고 있는 물질의 페르미 준위이 디랙 정 아래에 위치할 경우 정공(hole) 페르미 액 체가 생성된다 [40,41]. 그림 4에서와 같이 띠틈(band gap)이 $0.9 \mathrm{eV}$ 인 $\mathrm{SnSe}$ 의 전자친화도 (electron affinity, $\chi$ ) 는 약 $4.55 \mathrm{eV}$ 로 알려져 있으며, 또한 본 실험에서 $\mathrm{SnSe}$ 는 p-type의 비축퇴 반도체이므로 페르미 준위가 가전대 상단 $\left(E_{\mathrm{V}}\right)$ 근처에 형성되어져 있다 [42]. 이 경우, $\mathrm{SnSe}$ 의 페르미 준위까지 정공이 형성되게 되며 이는 $\mathrm{SnSe}-\mathrm{RGO}$ 복합체에서 전하농도를 증가시켜 전기전도도를 향상시키게 된다.

이상과 같이 $\mathrm{RGO}$ 복합화에 따른 전하농도의 증가를 직 접적으로 확인하는 방법은 홀 측정법(Hall measurement)이 지만, 본 실험에서는 신뢰성있는 측정이 어려워 제벡 계수 를 이용하여 간접적으로 확인하였다. 그림 $5(\mathrm{a})$ 는 $\mathrm{SnSe}-$ $\mathrm{RGO}$ 복합체의 온도에 따른 제벡 계수를 나타내며, 삽도에 나타낸 바와 같이 가압방향과 수직인 방향으로 측정을 수 

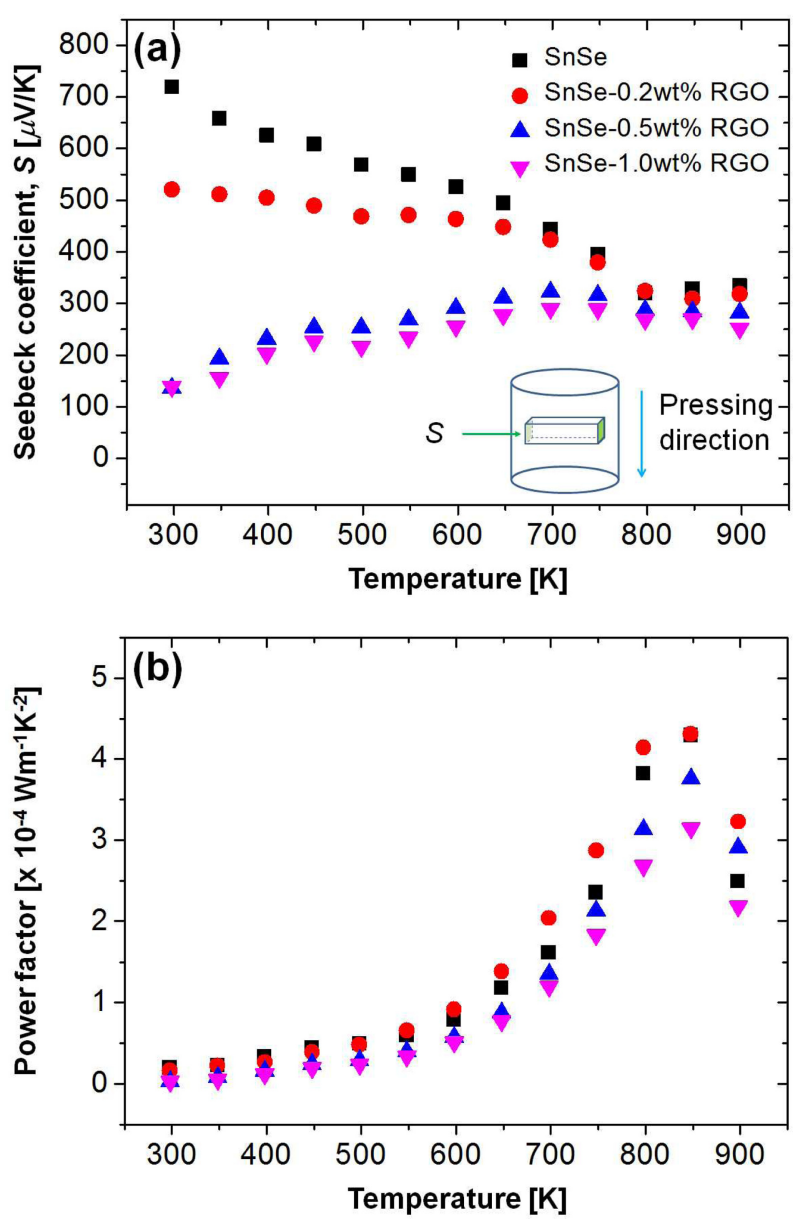

Fig. 5. (a) Temperature-dependent electrical conductivities and (b) temperature-dependent power factors of the SnSe-RGO composites.

행하였다. 제벡 계수는 아래의 식 (4)에 나타낸 바와 같이 전하농도와 역의 상관관계를 나타낸다 [43].

$$
S=\frac{8 \pi^{2} k_{B} T}{3 q h^{2}} m_{d}^{*}\left(\frac{\pi}{3 p}\right)^{2 / 3},
$$

여기에서 $k_{B}$ 는 볼츠만 상수 (Boltzmann constant), $q$ 는 전 하수송자의 전하량, $h$ 는 플랑크상수(Planck constant), $m_{d}{ }^{*}$ 는 상태밀도 유효질량, 그리고 $p$ 는 정공 농도를 나타낸다.

그림 5(a)에서와 같이 $\mathrm{RGO}$ 증가에 따라 제벡 계수가 급속히 감소하는데, 이는 $\mathrm{SnSe}-\mathrm{RGO}$ 복합체에서의 정공의 농도가 급속히 증가하고 있음을 의미하며따라서 정공 페르 미 액체의 형성이 그림 3 에서 관찰된 전기전도도의 급속 한 증가의 원인이 됨을 알 수 있다. 그런데, RGO 함량이 $0.5 \mathrm{wt} \%$ 까지는 정공의 증가에 따라 제벡 계수가 급속히 감소하지만, 이후에는 큰 감소를 나타내지 않으며 이는 전 기전도도에서 관찰되는 경향과 잘 일치한다. 앞서 살펴본
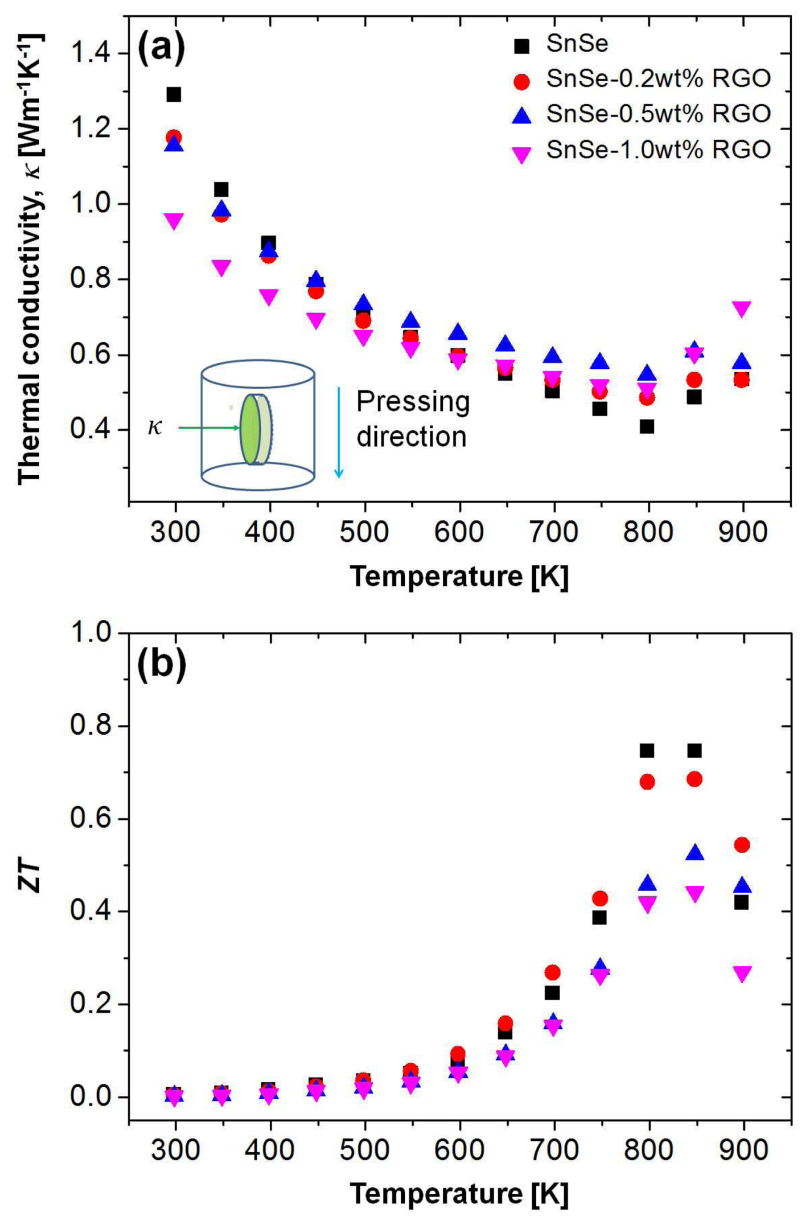

Fig. 6. (a) Temperature-dependent thermal conductivities and (b) temperature-dependent $Z T$ of SnSe-RGO composites.

바와 같이 $\mathrm{SnSe}-\mathrm{RGO}$ 복합체에서 정공의 생성은 $\mathrm{RGO}$ 와 $\mathrm{SnSe}$ 의 접촉에 기인하기 때문에, 이러한 현상은 $0.5 \mathrm{wt} \%$ 에서 이미 $\mathrm{SnSe}$ 와 $\mathrm{RGO}$ 간의 충분한 접촉(full coverage) 이 이루어졌으며 그 이후로는 새로운 접촉이 크게 발생하 지 않아 더 이상의 정공의 생성이 어려워졌기 때문으로 이 해된다.

그림 5(b)는 $\mathrm{SnSe}-\mathrm{RGO}$ 복합체의 온도에 따른 출력인자 (power factor $=S^{2} \sigma$ )를 나타낸다. 비록 그림 3에서와 같 이 $\mathrm{RGO}$ 와의 복합화에 따라 전기전도도의 증진이 가능하 였지만, 한편 RGO 첨가에 따른 제벡 계수의 급속한 감소 는 출력인자의 감소를 야기하였으며 이는 전체적인 열전성 능에 부정적인 영향을 가져온다.

그림 6(a)는 $\mathrm{SnSe}-\mathrm{RGO}$ 복합체의 온도에 따른 전체 열 전도도(total thermal conductivity, $\kappa$ )를 나타낸다. 그림 3 에서 살펴본 바와 같이 $\mathrm{RGO}$ 첨가에 따라 전기전도도가 증가함에도 불구하고 전체 열전도도는 $\mathrm{RGO}$ 함량 증가에 
따라 지속적으로 감소하는 경향이 확인되며, 이는 특히 상대적으로 저온 영역에서 더욱 명확하게 관찰된다. 그러 나 최대 출력인자가 관찰된 $800 \mathrm{~K}$ 이상의 고온에서는 오 히려 $\mathrm{RGO}$ 가 첨가되지 않은 시료에서 가장 낮은 열전도 도를 보이는데, 그 이유는 아직 명확하지 않으나 이는 입 계에 존재하는 $\mathrm{RGO}$ 의 포논 산란효과가 온도에 의존함을 의미한다.

이러한 고온영역에서의 출력인자 및 열전도도 특성으로 인하여 ZT는 그림 6(b)에서와 같이 RGO 함량이 증가함에 따라 지속적으로 감소하였으며, $\mathrm{RGO}$ 복합화를 하지 않은 다결정 $\mathrm{SnSe}$ 시료에서 가장 우수한 값이 얻어졌으며, 최대 $Z T$ 는 $848 \mathrm{~K}$ 에서 0.75 였다. 본 연구를 통해 비록 우수한 $Z T$ 를 구현하지는 못하였으나, $\mathrm{RGO}$ 복합화는 다결정 $\mathrm{SnSe}$ 복 합체의 입계에서 포논산란을 유발하여 격자 열전도도를 감 소시킬 수 있다는 것을 확인하였으며, 이를 통해 전기전도 도와 열전도도의 독립적 제어를 통해 $\mathrm{SnSe}-\mathrm{RGO}$ 복합체에 서 $\mathrm{PGEC}$ 의 구현이 가능함을 증명하였다.

\section{4. 결 론}

$\mathrm{RGO}$ 를 활용한 계면제어가 다결정 $\mathrm{SnSe}-\mathrm{RGO}$ 복합체 의 열전수송현상에 미치는 영향에 대한 연구를 수행하였 다. XRD 분석결과, $\mathrm{SnSe}-\mathrm{RGO}$ 복합체는 단일한 사방정 결정구조를 보였으며, $\mathrm{RGO}$ 의 함량에 따른 회절 피크의 이동이나 이차상은 관찰되지 않았다. $\mathrm{RGO}$ 는 복합체에서 전하농도를 증가시켜 전기전도도를 향상시켰고 이를 제벡 계수를 이용하여 확인하였다. 이 정공의 생성은 $\mathrm{RGO}$ 와 $\mathrm{SnSe}$ 의 접촉에 따른 정공 페르미 액체 형성에 기인한 것 으로 여겨진다. 한편, 이러한 전기전도도 향상에도 불구 하고 제벡 계수의 감소가 매우 크게 발생하여 출력인자 의 상승을 유도하지는 못하였다. 한편 RGO 첨가에 따른 열전도도 감소를 확인하였으며, 이를 통해 계면에 존재하 는 $\mathrm{RGO}$ 에 의해 여분의 포논 산란이 가능하다는 것을 입증하였다. 그러나 이러한 현상은 상대적으로 저온에서 크게 관찰되었으며, 최대 출력인자가 관찰된 고온에서는 오히려 열전도도가 증가하여 전체적인 열전성능지수는 $\mathrm{RGO}$ 함량이 증가함에 따라 감소하였다. 하지만 본 실험 을 통해 전기전도도와 열전도도의 독립적 제어가 가능함 을 증명하였고, 이러한 $\mathrm{RGO}$ 를 이용한 계면제어를 통한 $\mathrm{PGEC}$ 현상의 구현은 향후 도핑을 통한 추가적인 열전성 능 향상과 함께 $\mathrm{SnSe}$ 의 열전성능 향상에 적용가능성이 높을 뿐만 아니라 다른 열전소재의 성능 향상에도 적용 이 가능할 것으로 예상된다.

\section{감사의 글}

본 연구는 한국연구재단 중견연구자지원사업(2015R1A2A 2A01005929)을 통해 수행되었습니다.

\section{REFERENCES}

1. L. E. Bell, Science 321, 1457 (2008).

2. F. J. Disalro, Science 285, 703 (1999).

3. H. J. Goldsmid, Materials 7, 2577 (2014).

4. W. Xie, D. A. Hithchcock, H. J. Kang, J. He, X. Tang, M. Laver, and B. Hammouda, Appl. Phys. Lett. 101, 113902 (2012).

5. Y. Zheng, Q. Zhang, X. Su, H. Xie, S. Shu, T. Chen, G. Tan, Y. Yan, X. Tang, C. Uher, and G. J. Snyder, Adv. Energy Mater. 5, 1401391 (2015).

6. W. Liu, K. C. Lukas, K. McEnaney, S. Lee, Q. Zhang, C. P. Opeil, G. Chen, and Z. Ren, Energy Environ. Sci. 6, 552 (2013).

7. Y. Ma, Q. Hao, B. Poudel, Y. Lan, B. Yu, D. Wang, G. Chen, and Z. Ren, Nano Lett. 8, 2580 (2008).

8. B. Poudel, Q. Hao, Y. Ma, Y. Lan, A. Minnich, B. Yu, X. Yan, D. Wang, A. Muto, D. Vashaee, X. Chen, J. Liu, M. S. Dresselhaus, G. Chen, and Z. Ren, Science 320, 634 (2008).

9. S. I. Kim, K. H. Lee, H. A. Mun, H. S. Kim, S. W. Hwang, J. W. Roh, D. J. Yang, W. H. Shin, X. S. Li, Y. H. Lee, G. J. Snyder, and S. W. Kim, Science 348, 109 (2015).

10. X. Ji, B. Zhang, T. M. Tritt, J. W. Kolis, and Kumbhar, J. Electron. Mater. 36, 721 (2007).

11. C.-H. Kuo, M.-S. Jeng, J.-R. Ku, S.-K. Wu, Y.-W. Chou, and C.-S. Hwang, J. Electron. Mater. 38, 1956 (2009).

12. J. He, J. R. Sootsman, S. N. Girarad, J.-C. Zheng, J. Wen, Y. Zhu, M. G. Kanatzidis, and V. P. Dravid, J. Am. Chem. Soc. 132, 8669 (2010).

13. L.-D. Zhao, S. H. Lo, Y. Zhang, H. Sun, G. Tan, C. Uher, C. Wolverton, V. P. Dravid, and M. G. Kanatzidis, Nature 508, 373 (2014).

14. E. K. Chere, Q. Zhang, K. Dahal, F. Cao, J. Mao, and Z. Ren, J. Mater. Chem. A 4, 1848 (2016).

15. J. C. Li, D. Li, X. Y. Qin, and J. Zhang, Scripta Mater. 126, 6 (2017).

16. S. Sassi, C. Candolfi, J.-B. Vaney, V. Ohorodniichuk, P. Masschelein, A. Dauscher, and B. Lenoir, Appl. Phys. Lett. 104, 212105 (2014).

17. C.-L. Chen, H. Wang, Y.-Y. Chen, T. Day, and G. J. Snyder, J. Mater. Chem. A 2, 11171 (2014). 
18. Q. Zhang, E. K. Chere, J. Sun, F. Cao, K. Dahal, S. Chen, G. Chen, and Z. Ren, Adv. Energy Mater. 5, 1500360 (2015).

19. Y. Li, X. Shi, D. Ren, J. Chen, and L. Chen, Energies 8, 6275 (2015).

20. Y.-M. Han, J. Zhao, M. Jhou, X.-X. Jiang, H.-Q. Leng, and L.-F. Li, J. Mater. Chem. A 3, 4555 (2015).

21. B.-Z. Sun, Z. Ma, C. He, and K. Wu, Phys. Chem. Chem. Phys. 17, 29844 (2015).

22. Y.-X. Chen, Z.-H. Ge, M. Yin, D. Feng, X.-Q. Huang, W. Zhao, and J. He, Adv. Funct. Mater. 26, 6836 (2016).

23. T.-R. Wei, G. Tan, X. Zhang, C.-F. Wu, J.-F. Li, V. P. Dravid, G. J. Snyder, and M. G. Kanatzidis, J. Am. Chem. Soc. 138, 8875 (2016).

24. H. Guo, H. Xin, X. Qin, J. Zhang, D. Li, Y. Li, C. Song, and C. Li, J. Alloy. Compd. 689, 87 (2016).

25. N. K. Singh, S. Bathula, B. Gahtori, K. Tyagi, D. Haranath, and A. Dhar, J. Alloy. Compd. 668, 152 (2016).

26. Y. Li, F. Li, J. Dong, Z. Ge, F. Kang, J. He, H. Du, B. Li, and J.-F. Li, J. Mater. Chem. C 4, 2047 (2016).

27. Z.-H. Ge, D. Song, X. Chong, F. Zheng, L. Jin, X. Qian, L. Zheng, R. E. D.-Borkowski, P. Qin, J. Feng, and L.-D. Zhao, J. Am. Chem. Soc. 139, 9714 (2017).

28. S. Yang, J. Si, Q. Su, and H. Wu, Mater. Lett. 193, 146 (2017).

29. K. Peng, H. Wu, Y. Yan, L. Guo, G. Wang, X. Lu, and X. Zhou, J. Mater. Chem. A (2017).

30. Y.-X. Chen, Z.-H. Ge, M. Yin, D. Feng, X.-Q. Huang, W. Zhao, and J. He, Adv. Funct. Mater. 26, 6836 (2016).

31. Y. Zhu, S. Murali, W. Cai, X. Li, J. W Suk, J. R. Potts, and R. S. Ruoff, Adv. Mater. 22, 3906 (2010).

32. X. Du, I. Skachko, A. Barker, and E. Y. Andrei, Nat.
Nanotechnol. 3, 491 (2008).

33. X. Huang, Z. Zeng, Z. Fan, J. Liu, and H. Zhang, Adv. Mater. 24, 5979 (2012).

34. W. H. Nam, Y. S. Lim, W. Kim, H. K. Seo, K. S. Dae, S. Lee, W.-S. Seo, and J. Y. Lee, Nanoscale 23, (2017).

35. W. H. Nam, B. B. Kim, S. G. Seo, Y. S. Lim, J.-Y. Kim, W.S. Seo, W. K. Choi, H.-H. Park, and J. Y. Lee, Nano Lett. 14, 5104 (2014).

36. W. H. Shin, K. Ahn, M. Jeong, J. S. Yoon, J. M. Song, S. Lee, W. S. Seo, and Y. S. Lim, J. Alloy. Compd. 718, 342 (2017).

37. F. K. Lotgering, J. Inorg. Nucl. Chem. 9, 113 (1959).

38. S .T. Lee, M. J. Kim, G.-G. Lee, S. G. Kim, S. Lee, W.-S. Seo, and Y. S. Lim, Curr. Appl. Phys. 17, 732 (2017).

39. Y. Fu, J. Xu, G.-Q. Liu, J. Yang, X. Tan, Z. Liu, H. Qin, H. Shao, H. Jiang, B. Liang, and J. Jiang, J. Mater. Chem. C 4, 1201 (2016).

40. Y. M. Zuev, W. Chang, and P. Kim, Phys. Rev. Lett. 102, 096807 (2009).

41. A. N. Sidorov, A. Sherehiy, R. Jayasinghe, R. Stallard, D. K. Benjamin, Q. Yu, Z. Liu, W. Wu, H. Cao, Y. P. Chen, Z. Ziang, and G. U. Sumanasekera, Appl. Phys. Lett. 99, 013115 (2011).

42. B-S. Enue, M. T. S. Nair, and P. K. Nair, ECS J. Solid State Sc. 3, Q169 (2014).

43. A. F. Ioffe, Physics of Semiconductors, Academic Press, New York (1960).

44. Y. S. Lim, M. Song, S. Lee, and W. -S. Seo, Korean J. Met. Mater. 55, 427 (2017)

45. S. Bae, S. Lee, H.-S. Sohn, and H. S. Lee, Met. Mater. Int. 23, 1056 (2017). 